\title{
Preliminary Investigation Related to Physicochemical, Crystallinity, Microstructure and Engineering properties of Starch Isolated from Chempadak seed as Potential Food Ingredient for Industrial Application
}

\author{
Phisut Naknaen", Chaiyaphan Tharasuk, Jittikarn Junjerdee \\ ${ }^{a}$ Faculty of Agricultural Product Innovation and Technology, Srinakharinwirot University, 114 Sukhumvit 23 Wattana \\ Bangkok 10110 Thailand \\ *Corresponding Author: phisut@g.swu.ac.th
}

\begin{abstract}
The aim of this research was to investigate the physicochemical and engineering properties of starch isolated from chempadak seed for utilization as food ingredient in industrial application. It was found that starch yield was $25.76 \%$ and other components such as proteins, lipids, crude fiber and ash were presented in starch as minor constituents, suggesting that the chempadak seed starch (CSS) was high purity. The CSS granules were irregular, round to bell shapes or semi-oval with average size of $6.19 \mu \mathrm{m}$. The A-type XRD pattern as detected in the CSS was similar to the cereal starches. Thermal transition temperature assessed by DSC was $81.08^{\circ} \mathrm{C}\left(\mathrm{T}_{\text {peak }}\right)$ and the gelatinization enthalphy $(\Delta \mathrm{H})$ was $17.68 \mathrm{~J} / \mathrm{g}$. The flow behavior of the CSS at concentration of $3-6 \%$ (db) exhibited Non-newtonian shear thinning behavior as fitted to the Power law model. The flow behavior index of starch decreased with increasing starch concentration. The pasting characteristics of the $\mathrm{CSS}$ at $\mathrm{pH}$ in range of 3.6 to 7.0 were investigated. Pasting temperature of the CSS decreased with decreasing $\mathrm{pH}$ from 7.0 to 3.6. No peak viscosity and breakdown were found during cooking at $\mathrm{pH} 4.6$ to 7.0, indicating that the CSS could be used in low acid canned food. The CSS starch gel presented the best freeze-thaw stability, which no syneresis was observed in 5 cycles, suggesting that application of the CSS in frozen food is proper. In addition, the CSS could form gel with low concentration (4\%) when compared to other commercial starches. Therefore, the CSS could be recommended as alternative starch to apply in food industry, particularly utilization as gelling agent and in frozen food products.
\end{abstract}

Keywords: chempadak seed starch, engineering properties, industrial application

\section{Introduction}

Starch is a renewable and biodegradable carbohydrate polymer from a great variety of crops. It is a raw material with a wide variety of applications ranging from its use in the food industry in order to enhance texture and consistency, to the manufacture of paper, adhesives and biodegradable packaging. Several types of starches, including rice, corn and potato starches, have been used for food and non-food industries. Introducing new starch raw material sources with interesting characteristics has been attracting the attention of industrialists as it could influence the world market. The search for novel starches has resulted in recent focus on seeds.

Chempedak (Artocarpus integer) belongs to the family Moraceae and is widely grown in Southeast Asia including Bangladesh, India and Thailand. Chempedak fruit are normally eaten as fresh. The seed is eaten as cooked, roasted or fried products. The chempedak seed contain considerably high amount of starch that qualify as a sustainable source of starch for industries (1). However, the literatures related to the information on isolation and properties of the CSS have rarely been investigated. It is therefore interesting to find out about the properties of starch extracted from chempadak seeds in order to apply in food, pharmaceutical and non-food applications, or to replace other expensive starches. Thus, the aim of this study was to investigate the properties related to physicochemical, microstructure, crystallinity and engineering properties of starch isolated from chempedak seeds. The data obtained from the present study could be used as a guideline to apply the CSS as potential ingredient for industrial application. 


\section{Materials and Methods}

\subsection{Fruit seed samples}

Chempedak seeds (Artocarpus integer L.) were collected from ripe fruit grown in the Southern part of Thailand. The fruits were washed with tap water, peeled off, and the seeds were manually separated from the pulp and the mucilage peel of the seeds was removed manually. The seeds were stored at $-20^{\circ} \mathrm{C}$ for further starch isolation.

\subsection{Starch isolation}

Starch isolation was carried out following the modified basic procedure washing steps described by Naknaen ${ }^{(2)}$. The alkaline extraction process was applied to extract starch from chempedak seeds. After extraction, extracted starch was dried overnight in an air oven at $50^{\circ} \mathrm{C}$, ground to pass through a 100 mesh sieve and stored at room temperature in sealed plastic containers. Figure 1 shows the appearance of the CSS.

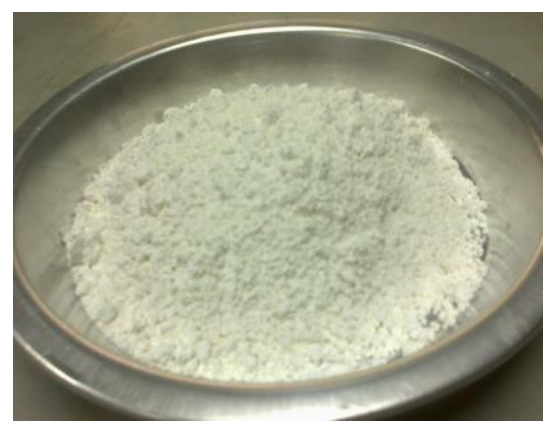

Fig. 1. Chempedak seed starch (CSS)

\subsection{Analysis of chemical compositions}

The moisture, protein, lipid, ash, and fiber contents were analyzed according to AOAC ${ }^{(3)}$. The amylose content was determined using the modified method of Gunaratne and Hoover ${ }^{(4)}$. Standard potato amylose (Sigma Chemical, USA) was used as references.

\subsection{Morphological characteristics of starch granules}

Starch sample was mounted on a scanning electron microscopy (SEM) stub and coated with gold. Scanning electron micrograph was taken with a JEOL JSM-5600LV microscope (JEOL, England). The accelerating voltage and the magnification are shown on the micrographs.

\subsection{Particle size analysis}

Particle size distribution of starch was measured using a laser particle size analyzer (LS230, Coulter Electronics, High Wycombe, UK) and water was used as a medium.

\subsection{X-ray diffraction}

The diffraction pattern of starch was obtained in an X-ray diffractometer (Philips brand). The diffractogram was obtained in the range of $5-40^{\circ}$ in the scale of the angle $2 \theta$. The percentage of relative crystallinity was calculated as the percentage of the peak area related to the total area of diffraction in the diffractogram.

\subsection{Effect of temperature on swelling power and solubility}

Swelling power and solubility were determined following the method proposed by Naknaen ${ }^{(2)}$. There were five temperatures applied to study including 55, $65,75,85$ and $95^{\circ} \mathrm{C}$. Swelling power was calculated as gram of swollen starch per gram of dry sample, and the solubility was the percentage of the dried supernatant to the original dried sample.

\subsection{Starch gelatinization}

Starch gelatinization was studied by using a differential scanning calorimeter (DSC 7, Perkin Elmer, Norwalk, CT, USA), using 1:3 (w/w) starch - water mixtures. The sample was hermetically sealed in a pre-weighted aluminum pan at room temperature and re-weighed in a microbalance. After sealing of the pan and leaving to equilibrate for about $12 \mathrm{~h}$, the sample was heated from $30-100^{\circ} \mathrm{C}$ at $10^{\circ} \mathrm{C} / \mathrm{min}$. An empty pan was used as a reference. The temperatures of the characteristic transitions, onset temperature $\left(T_{\text {onset }}\right)$, peak temperature $\left(T_{\text {peak }}\right)$ and end temperature $\left(T_{\text {end }}\right)$ were recorded and the temperature ranges $\left(T_{\text {end }}-T_{\text {onset }}, \Delta T\right)$ were calculated. The enthalpy $(\Delta H)$ of the transition was expressed as $\mathrm{J} / \mathrm{g}$ on a dry weight basis.

\subsection{Flow behavior: Effect of concentration of starch on flow behavior}

Apparent viscosity of starches was recorded using a Brookfield viscometer (model RVF, Stoughton, MA). The various concentrations of starch slurry (3-6 \%, dry basis, db) was cooked in a boiling bath for $30 \mathrm{~min}$, and cooled to $60^{\circ} \mathrm{C}$. Paste viscosity was 
determined at different shear rate speeds $(2-100 \mathrm{rpm}){ }^{(5)}$. Flow behavior index was calculated by using Power law model.

$$
\sigma=K(\gamma)^{n}
$$

$\mathrm{K}=$ flow consistency index; $\mathrm{n}=$ flow behavior index

$\sigma=$ shear stress; $\gamma=$ shear rate

\subsection{Effect of pH on pasting properties}

RVA (RVA4D, Newport Scientific, Warriewood, Australia) was employed to measure the pasting properties of starch ( $3 \mathrm{~g} \mathrm{db}, 28 \mathrm{~g}$ total weight). The measured characteristics recorded were: pasting temperature, peak viscosity, time to peak, minimum viscosity and final viscosity. The starch paste stability was determined by RVA under various $\mathrm{pH}$ mediums such as 3.6, 4.6, 5.6 and 7.0 using standard buffer.

\subsection{Gelation studies}

Samples of starch, 2-14\% (w/v), were prepared in test tubes with $5 \mathrm{ml}$ of distilled water. Least gelation concentration was determined as that concentration when the sample from the inverted test tube did not fall down or slip ${ }^{(6)}$.

\subsection{Turbidity}

The starch suspension turbidity was measured as described by Rondan-Sanabria and Finardi-filho ${ }^{(6)}$. The turbidity was monitored during seven days of storage.

\subsection{Acid hydrolysis}

Starch was hydrolyzed with $2.2 \mathrm{~N} \mathrm{HCl}$ at $35^{\circ} \mathrm{C}(1 \mathrm{~g} \mathrm{db}$, starch $/ 40 \mathrm{~mL}$ acid $)$ for periods ranging from 0 to 12 days. The extent of hydrolysis was estimated by the Somogyi-Nelson method ${ }^{(7)}$. Three replicates per sample were analyzed.

\subsection{Syneresis: stability to freezing}

The stability of the gel was evaluated by syneresis degree at freezing conditions as proposed by Rondan-Sanabria and Finardi-filho (6) with some modifications. The starch gel was conditioned at $-10^{\circ} \mathrm{C}$ for 5 days. Syneresis was measured during five days of gel storage.

\subsection{Statistical analysis}

The data obtained for textural properties were subjected to a one way analysis of variance (ANOVA) followed by Duncan's multiple range test and the significance level was $\mathrm{P}<0.05$.

\section{Results and Discussion}

\subsection{Chemical composition}

The data on yield and composition of the CSS were presented in Table 1. Starch yield was 25.76 $\mathrm{g} / 100 \mathrm{~g}$ seed. These values were higher than the 17.5 $\mathrm{g} / 100 \mathrm{~g}$ reported for the chempedak seed by Tongdang ${ }^{(1)}$. This high yield might have been affected by the method used for extraction and the maturity stage of seed. The moisture content of the starch was low (11.28\%) and within the acceptable range for marketing and storage. Other components such as protein, lipid, crude fiber and ash were presented in starch as minor constituents. The ash, protein and lipid content of the CSS were higher than that reported by Tongdang ${ }^{(1)}$. High protein content may affect surface charge, rate of hydration and thus interfere with starch swelling and gelatinization. Lipids can influence starch functionality by forming helical inclusion complexes with amylose and thus inhibit swelling and lower paste clarity ${ }^{(8)}$. The amylose content of the CSS was comparable to other commercial starches. Amylose content is an important starch characteristic as it affects the functional properties of starch in its many uses in the food industry and other applications.

Table 1. Chemical compositions of the CSS

\begin{tabular}{|c|c|}
\hline Composition $(\boldsymbol{\%}, \mathbf{d b})$ & CSS \\
\hline Moisture & 11.28 \\
\hline Protein & 0.97 \\
\hline Lipid & 0.51 \\
\hline Ash & 0.35 \\
\hline Amylose & 26.46 \\
\hline Yield pure starch & 25.76 \\
\hline
\end{tabular}




\subsection{Morphological characteristic and size} distribution of starch granule

Figure 1 showed the scanning electron micrographs of the CSS granules. The shapes of the CSS granules were irregular, round to bell shapes or semi-oval. This result was in agreement with the work of Tongdang (1). Figure 2 showed the granule size distribution of the CSS. Granule size of the CSS ranged from 0.16 to $18.86 \mu \mathrm{m}$ with average size of $6.19 \mu \mathrm{m}$. Lindeboom et al. ${ }^{(9)}$ classified starch granule sizes as: large $(>25 \mu \mathrm{m})$, medium $(10-25 \mu \mathrm{m})$, small $(5-10 \mu \mathrm{m})$ and very small $(<5 \mu \mathrm{m})$. Thus, granule size of the CSS could be classified as small size. This study agreed well with previous work in which size of starch extracted from chempedak seeds was $6.47 \mu \mathrm{m}$ on average ${ }^{(1)}$. The granule sizes of some other fruit seed starches have been reported as $10-16 \mu \mathrm{m}$ or $15-21 \mu \mathrm{m}$ for mango, $10 \mu \mathrm{m}$ for longan and $10 \mu \mathrm{m}$ for rambutan ${ }^{(2)}$. The granule size of starch could influence the functional properties of starch, especially swelling power and viscosity and hence its applications. Smaller granule size might develop a low paste viscosity and might be suitable to use as bulking agent.

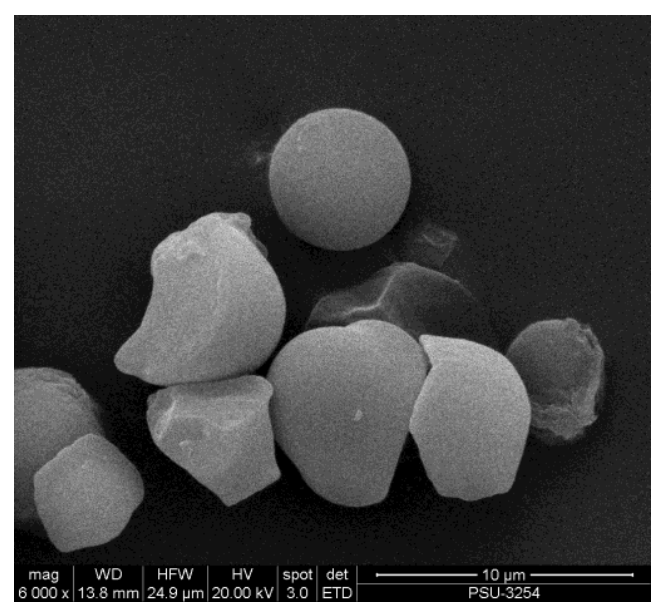

Fig. 1. Granule micrograph of the CSS.

\subsection{X-ray diffraction pattern and Crystallinity}

The X-ray diffraction pattern (XRD) was used to reveal the presence and characteristics of crystalline structures of starch granules. Native starches are known to display 3 characteristic diffraction patterns: A-type, B-type and C-type. An A-type diffraction pattern is common in cereal starches and has characteristic peaks at around 15, 17, 17.9 and 23 while the B-type pattern is common in tuber starches with peaks at around 5.8, 15 and a single peak at 17 (instead of a doublet at 17 and 17.9 as in A-type) and two small peaks at around 23 and 24. However, a C-type X-ray diffraction pattern which is common in pea starches is a mixture of A- and B-type patterns ${ }^{(10)}$. The XRD pattern of the CSS is shown in Figure 3. The CSS showed the typical A type X-ray pattern with appearance of peaks of $2 \theta$ at $15^{\circ}, 17^{\circ}, 17.9^{\circ}$ and $23^{\circ}$. The degree of crystallinity was $32 \%$. Thus, the XRD pattern of the CSS was comparable to starches extracted from cereals such as rice, wheat and corn.

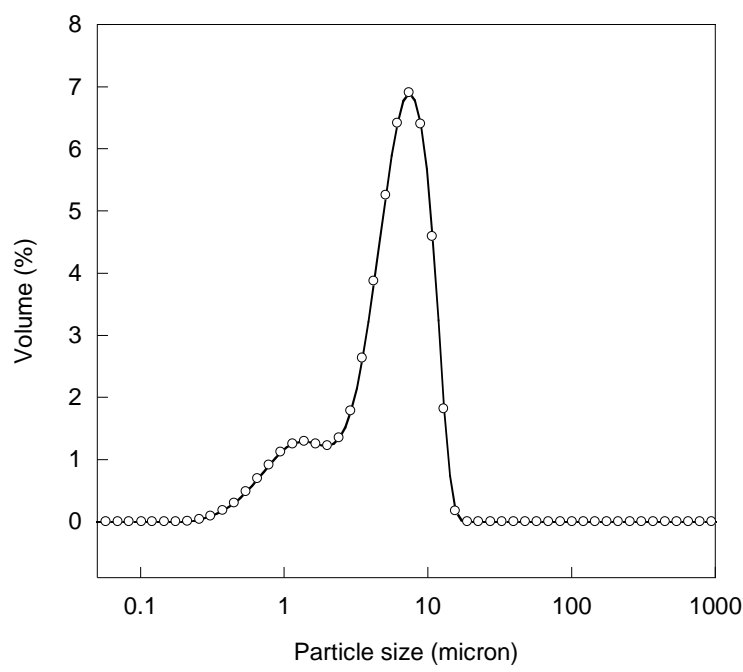

Fig. 2. Granule size distribution of the CSS.

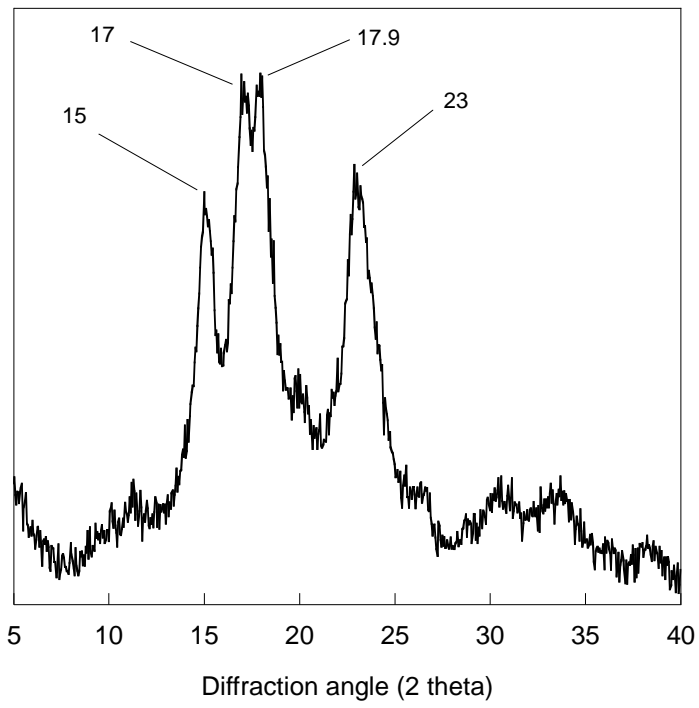

Fig. 3. XRD pattern of the CSS. 


\subsection{Swelling power and solubility}

Swelling and solubility patterns provide information on the nature of the associative bonding within the starch granule. The starch granules are discrete semi crystalline aggregates consisting of amylose and amylopectin as major components. The ratio of these fractions in the starch granule and the manner in which they are arranged inside the granule affect the swelling and solubility of the starch. Swelling ability contributes to important characteristics of most starchy food products, such as pasting and rheological behavior during heating with excess water ${ }^{(11)}$. In this study, swelling power and solubility of the CSS were assessed over temperatures of $55-95^{\circ} \mathrm{C}$ at $10^{\circ} \mathrm{C}$ intervals. It was found that temperature exerted a pronounced effect on swelling power and solubility of the CSS as presented in Figure 5. The swelling power and solubility increased gradually from 55 to $65^{\circ} \mathrm{C}$, increased sharply between 65 to $95^{\circ} \mathrm{C}$. Factors such as lipid and amylose contents affect the swelling powder and solubility of starch. High level of amylose and lipid strongly inhibited swelling property of starch granules. In addition, amylose acts as both diluent and as a direct inhibitor of swelling because of the complex entanglements of its long linear chains and indirectly by forming insoluble complexes with lipids ${ }^{(12)}$. The swelling power and solubility of the CSS reported by Tongdang ${ }^{(1)}$ were in agreement with the result reported in this experiment. Comparing with other commercial starches such as potato, corn and rice starches, swelling power and solubility of the CSS was similar to the corn and rice starches. However, lower swelling power and solubility was detected compared to the potato starch (13)

\subsection{Gelatinization}

Starch gelatinization is an order-disorder phase transition of starch granules in presence of water and heat resulting in loss of the crystalline order, swelling of the granules and solubilization of starch molecules. The transition is endothermic and heat change is called the gelatinization enthalpy. Gelatinization characteristics of the CSS were presented in Table 2. The temperature $\left(\mathrm{T}_{\text {peak }}\right)$ and enthalpy of gelatinization $(\Delta \mathrm{H})$ were $81.08^{\circ} \mathrm{C}$ and $17.68 \mathrm{~J} / \mathrm{g}$, respectively. The enthalpy of the gelatinization indicates the required energy for disruption hydrogen bond within crystalline zone. The difference in gelatinization temperature among starches has been attributed to the interplay of some factors such as the starch composition, the molecular structure of the amylopectin and granules architecture. In addition, the degree of crystallinity also affected the thermal properties. Low degree of crystallinity leads to a lower gelatinization temperature and $\Delta \mathrm{H}$. Thus, the lower gelatinization temperature and $\Delta \mathrm{H}$ are indicative of its weaker granular structure. Moreover, the CSS had a narrower gelatinization temperature range $(\Delta \mathrm{T})$. The low gelatinization range could be due to the fairly uniform granule sizes. The low gelatinization temperature range would enable the CSS to be desirable for food processing as it will form viscous paste with smooth texture and absence of lumps. According to the previous literatures, either gelatinization temperature $\left(\mathrm{T}_{\mathrm{p}}\right)$ or enthalpy of gelatinization $(\Delta \mathrm{H})$ of the CSS tended to be higher than other commercial starches such as potato $\left(\mathrm{T}_{\mathrm{p}}=65^{\circ} \mathrm{C} ; \Delta \mathrm{H}\right.$ $=14 \mathrm{~J} / \mathrm{g})$, corn $\left(\mathrm{T}_{\mathrm{p}}=69^{\circ} \mathrm{C} ; \Delta \mathrm{H}=12 \mathrm{~J} / \mathrm{g}\right)$, wheat $\mathrm{T}_{\mathrm{p}}=$ $\left.52^{\circ} \mathrm{C} ; \Delta \mathrm{H}=10 \mathrm{~J} / \mathrm{g}\right)$ and rice $\left(\mathrm{T}_{\mathrm{p}}=67^{\circ} \mathrm{C} ; \Delta \mathrm{H}=13 \mathrm{~J} / \mathrm{g}\right)$ starches ${ }^{(13)}$. This result indicated that higher temperature and energy were required to cook the CSS when compared to other commercial starched as mentioned above.

\subsection{Flow behavior index: Effect of starch concentration}

Table 3 showed the effect of starch concentration on flow behavior index and flow consistency index. It was found that the viscosity behavior of the CSS could be classified as pseudoplastic or shear-thinning as indicated by the flow behavior index was less than 1. A decrease in flow behavior index was found with increasing the CSS concentration, suggested that high concentration of the CSS enhanced the shear-thinning behavior. Regarding to the flow consistency index that related to the viscosity of starch, an increase in flow consistency index was observed with increasing the CSS concentration, suggesting that the interaction of starch chains was promoted by high concentration of starch.

\subsection{Starch paste stability: Effect of pH}

The starch paste stability of the CSS at $\mathrm{pH}$ in the range of 3.6 to 7.0 was studied by RVA and presented in Table 4. The CSS exhibited pasting temperature in the ranges of $81-90^{\circ} \mathrm{C}$. The lowest pasting temperature and peak viscosity were observed at 
$\mathrm{pH}$ 3.6, suggesting that the occurrence of acid hydrolysis of starch granules was taken place. When increasing $\mathrm{pH}$ from 4.6 to 7.0 , no difference in pasting temperature and peak viscosity was found. The highest breakdown and setback was detected in all starch pastes adjusted $\mathrm{pH}$ to 3.6 while no differences in breakdown and setback were found in all starch pastes adjusted $\mathrm{pH}$ in the range of 4.6 to 7.0. It is thus evident from the results that the CSS can be used as an alternate starch source in some food products such as low acid canned foods $(\mathrm{pH}>4.6)$ and noodle type products. For the later example, retrogradation of starch is important to noodle quality since CSS could retrograde well, hence they might be possible to substitute mung bean and rice starches.
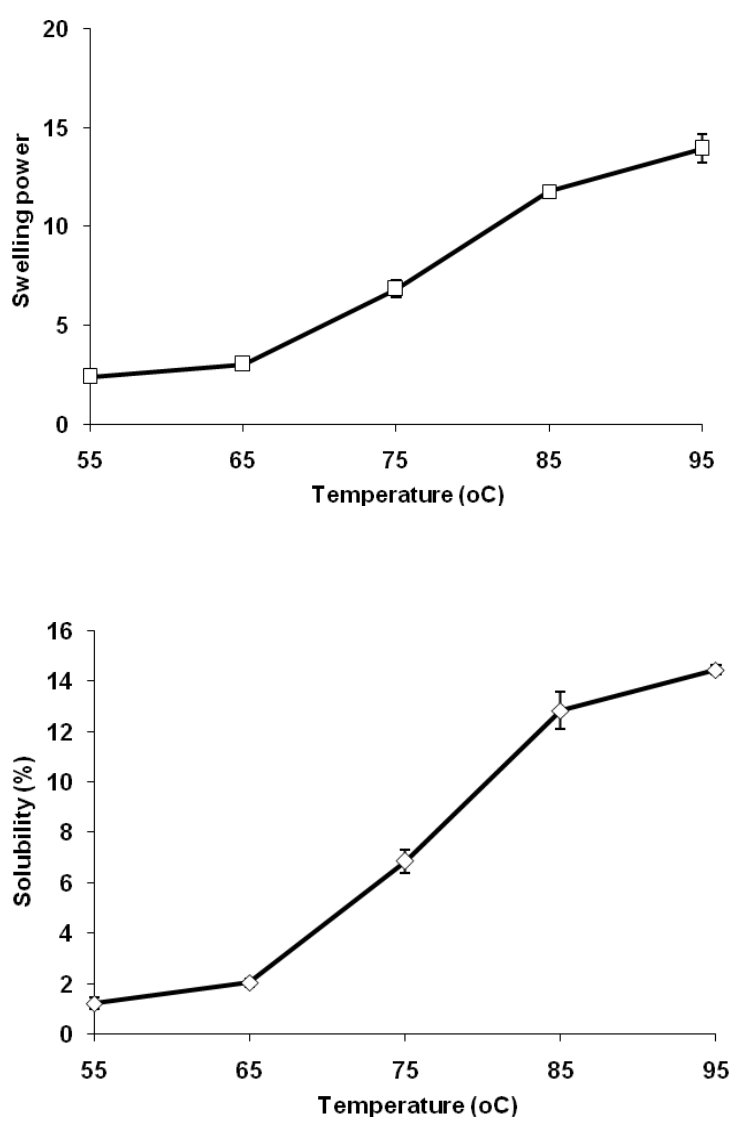

Fig. 5. Swelling power and solubility of the CSS.

Table 2. Thermal properties of the CSS.

\begin{tabular}{|c|c|c|c|c|}
\hline \multicolumn{3}{|c|}{ Temperature } & \multirow{2}{*}{$\Delta \mathrm{T}\left({ }^{\circ} \mathrm{C}\right)$} & $\begin{array}{c}\text { Enthalpy } \\
(\mathrm{J} / \mathrm{g})\end{array}$ \\
\hline $\mathrm{T}_{\text {onset }}$ & $\mathrm{T}_{\text {peak }}$ & $\mathrm{T}_{\text {end }}$ & & 17.68 \\
\hline 75.02 & 81.08 & 87.18 & 12.16 & 16 \\
\hline
\end{tabular}

Table 3 Effect of the CSS concentration on flow behavior index and flow behavior consistency

\begin{tabular}{ccc}
\hline Starch concentration $(\%, \mathrm{db})$ & $\mathrm{n}$ & $\mathrm{K}$ \\
\hline 3 & $0.73^{\mathrm{a}}$ & $179.31^{\mathrm{a}}$ \\
4 & $0.51^{\mathrm{b}}$ & $245.47^{\mathrm{b}}$ \\
5 & $0.44^{\mathrm{b}}$ & $260.23^{\mathrm{C}}$ \\
6 & $0.32^{\mathrm{c}}$ & $295.57^{\mathrm{d}}$ \\
\hline
\end{tabular}

Note: Values followed by different letters within the same column are significantly different $(\mathrm{p}<0.05)$.

Table 4 Effect of $\mathrm{pH}$ on the pasting properties of the CSS

\begin{tabular}{|c|c|c|c|c|}
\hline \multirow{2}{*}{ Parameters } & \multicolumn{4}{|c|}{$\mathrm{pH}$} \\
\cline { 2 - 5 } & 3.6 & 4.6 & 5.6 & 7.0 \\
\hline Pasting temperature $\left({ }^{\mathrm{o}} \mathrm{C}\right)$ & $81^{\mathrm{b}}$ & $89^{\mathrm{a}}$ & $90^{\mathrm{a}}$ & $90^{\mathrm{a}}$ \\
\hline Peak viscosity $(\mathrm{cP})$ & $2236^{\mathrm{c}}$ & $2870^{\mathrm{b}}$ & $2911^{\mathrm{b}}$ & $2945^{\mathrm{a}}$ \\
\hline Breakdown $(\mathrm{cP})$ & $520^{\mathrm{a}}$ & $395^{\mathrm{c}}$ & $360^{\mathrm{c}}$ & $459^{\mathrm{b}}$ \\
\hline Final viscosity $(\mathrm{cP})$ & $4000^{\mathrm{d}}$ & $4123^{\mathrm{c}}$ & $4234^{\mathrm{b}}$ & $4649^{\mathrm{a}}$ \\
\hline Setback $(\mathrm{cP})$ & $1215^{\mathrm{d}}$ & $1253^{\mathrm{c}}$ & $1322^{\mathrm{b}}$ & $1504^{\mathrm{a}}$ \\
\hline
\end{tabular}

Note: Values followed by different letters within the same column are significantly different $(\mathrm{p}<0.05)$.

\subsection{Gelation}

When a cooked paste of starch cools without agitation, intermolecular bonds are formed both within and between the swollen starch granules and their fragments. The least gelation concentration (LCG) was measured as the index of gelation capacity and presented in Table 5. The lowest concentration to obtain the firm gel of the CSS is $4 \%$. The observation can be explained in terms that it is the linear fraction that readily set up into a solid gel. The low gel concentration of the CSS compared to corn starch (6\%) and tapioca starch $(8 \%)$ may be proper for the formulation of curd or as an additive to other gel forming materials in food products. The differences in the amylose-amylopectin ratio could be responsible for LCG as it is the amylose that readily forms gel due to the fact that straight chains can orient themselves in a parallel alignment so that a large number of hydroxyl groups along the chain are in close proximity to those on adjacent chains resulting in gelation while the alignment is inhibited in case of amylopectin due to its branched structure. 
Table 5 Least gelation concentration (LGC) of the CSS

\begin{tabular}{|c|c|}
\hline Conc. $(\mathbf{g} / \mathbf{1 0 0 g})$ & CSS \\
\hline 2 & - Liquid \\
\hline 4 & + Firm gel \\
\hline 6 & + Firm gel \\
\hline 8 & + Firm gel \\
\hline 10 & + Very firm gel \\
\hline 12 & + Very firm gel \\
\hline 14 & + Very firm gel \\
\hline
\end{tabular}

\subsection{Turbidity}

The pattern of turbidity of the gelatinized CSS suspensions stored at $4^{\circ} \mathrm{C}$ for five days was shown in Table 6. A sharp decrease in transmittance values was observed in the first day of storage. Thereafter, no change in transmittance was found. The increase in turbidity results from changes in density distribution due to phase separation during aging of gelatinized starch solutions. This result might be suggested that the CSS could be used in the noodle type products.

\subsection{Acid hydrolysis}

Hydrolysis of the CSS by acid during storage was also presented in Table 6. The CSS subjected to acid treatment have been shown to initially exhibit a faster rate of hydrolysis followed by a slower rate thereafter. The faster rate has been attributed to the hydrolysis of the amorphous domains (amorphous background and the thin amorphous lamella within the crystalline region) of the starch granule, whereas during the second stage, the crystalline regions are slowly degraded ${ }^{(13)}$. At the end of the twelve day of hydrolysis, the CSS were hydrolysed to the extent of $8.2 \%$.

\subsection{Syneresis: stability to refrigeration}

Retrogradation is an important property when starch is employed to thicken sauces, pies and dips. Retrogradation is the process in which solubilized starch molecules reassociate through formation of junction zones, leading to a gel network in the case of a concentrated solution or phase separation for a dilute solution. Starch gels are metastable non-equilibrium systems and therefore undergo structural changes during storage. Syneresis characterizes the starch stability during storage and is also index of starch retorgradation degree at low temperature. This phenomenon is undesired for the use of starch in both food and non-food industries. The amount of water released is a measure of the stability of the paste. The CSS pastes presented high stability when stored under frozen storage $\left(-20^{\circ} \mathrm{C}\right)$, not presenting syneresis during five freeze-thaw cycles. The implication of this in food application is that both starches have good freeze-thaw stability and is suitable for use in products that are stored frozen and thawed for consumption.

Table 6 Turbidity and acid hydrolysis of CSS and during storage

\begin{tabular}{|c|c|c|c|}
\hline $\begin{array}{c}\text { Storage } \\
\text { time } \\
(\text { day })\end{array}$ & $\begin{array}{c}\text { Transmittance } \\
(\%)\end{array}$ & $\begin{array}{c}\text { Storage } \\
\text { time } \\
(\text { day })\end{array}$ & $\begin{array}{c}\text { Acid } \\
\text { hydrolysis } \\
(\% \text { glucose })\end{array}$ \\
\hline 0 & $8.33^{\mathrm{a}}$ & 0 & $0^{\mathrm{d}}$ \\
\hline 1 & $1.40^{\mathrm{b}}$ & 3 & $1.8^{\mathrm{c}}$ \\
\hline 3 & $1.35^{\mathrm{b}}$ & 6 & $6.2^{\mathrm{b}}$ \\
\hline 5 & $1.23^{\mathrm{b}}$ & 9 & $6.5^{\mathrm{b}}$ \\
\hline 7 & $1.25^{\mathrm{b}}$ & 12 & $8.2^{\mathrm{a}}$ \\
\hline
\end{tabular}

Note: Values followed by different letters within the same column are significantly different $(\mathrm{p}<0.05)$.

\section{Conclusions}

The applicability or utilization of starch in the food industry depends on its physicochemical properties. This study has shown that starches from the CSS have good gelation capacity and low syneresis under freeze-thaw cycle, indicating that it can be used as thickener and in products where gelation is required, as well as for frozen products. The retrogradation tendency implies that it can be a useful component of ingredients in food products where retrogradation is desired, such as noodle industry.

\section{Acknowledgment}

The authors thank the Srinakharinwirot university for financial support. 


\section{References}

(1) Tongdang, Taewee : "Some Properties of Starch Extracted from Three Thai Aromatic Fruit Seeds", Starch/Starke, Vol. 60, pp. 199-207, 2008

(2) Naknaen, Phisut : "Physicochemical, Thermal, Pasting and Microstructure Properties of Hydroxypropylated Jackfruit Seed Starch Prepared by Etherification with Propylene Oxide", Food Biphysics, Vol. 9, pp. 249-259, 2014

(3) AOAC Association of Official Analysis Chemistry, 16th Ed., Official Methods of Analysis of AOAC international, Washington, DC, 2000.

(4) Anil Gunaratne, and Ratnajothi Hoover : "Effect of heat moisture treatment on the structure and physicochemical properties of tuber and root starches", Carbohydrate Polymer, Vol. 49, pp. 425-437, 2002

(5) Luis Arturo Bello-Pérez, Yadira Pano de Léon, Edith Agama-Acevedo, and Octavio Paredes-López, Irapuato : "Isolation and Partial Characterization of Amaranth and Banana Starches", Starch/Starke, Vol. 50, pp. 409-413, 1998

(6) Gerby Giovanna Rondán-Sanabria, Flavio Finardi-Filho : "Physical-chemical and functional properties of maco root starch (Lepidium meyenii Walpers)", Food Chemistry, Vol 114, pp. 492-498, 2009

(7) Lahiru Jayakody, Ratnajothi Hoover, Qiang Liu, E. Weber : "Studies on tuber and root starches. I. Structure and physicochemical properties of innala (Solenostemon rotundifolius) starches grown in Sri Lanka", Food Research International, Vol 38, pp. 615-629, 2005

(8) Luis Arturo Bello-Pérez, Fernando Ortíz-Maldonado, Juan Villagómez-Mendez and Jorge Toro-Vazquez : "Effect of Fatty Acids on Clarity of Starch Pastes", Starch/Starke, Vol. 50, pp. 383-398, 1998

(9) Nienke Lindeboom, Peter Chang, and Robert Tyler : "Analytical, Biochemical and Physicochemical Aspects of Starch Granule Size, with Emphasis on Small Granule Starches: A Review", Starch/Starke, Vol. 56, pp. 89-99, 2004

(10) Louis Nwokocha, and Peter Williams : "Some properties of white and yellow plantain (Musa paradisiacal, Normalis) starches". Carbohydrate polymer, Vol. 76, pp. 133-138, 2009
(11) Louis Nwokocha, and Peter Williams : "Comparative study of physicochemical properties of breadfruit (Artocarpus altilis)". Carbohydrate polymer, Vol. 85, pp. 294-302, 2011

(12) Sathaporn Srichuwong, Titi Candra Sunarti, Takashi Mishima, Naoto Isono, and Makoto Hisamatsu : "Starches from different botanical sources II: Contribution of starch structure to swelling and pasting properties", Carbohydrate Polymer, Vol. 62, pp. 25-34, 2005

(13) Narpinder Singh, Jaspreet Singh, Lovedeep Kaur, Navdeep Singh Sodhi, and Balmeet Singh Gill : Morphological, thermal and rheological properties of starches from different botanical sources, Food Chemistry, Vol. 81, pp. 219-231, 2003 